\title{
Auxiliendo, Primum Non Nocere: A Preliminary View of the DEVOTE Trial Comparing Cardiovascular Safety of Insulin Degludec Versus Insulin Glargine in Type 2 Diabetes
}

Sanjay Kalra

Received: January 6, 2017 / Published online: February 14, 2017

(C) The Author(s) 2017. This article is published with open access at Springerlink.com

\begin{abstract}
A demonstration of cardiovascular safety is mandatory for all newly developed glucose-lowering agents, including insulin analogues. The vascular benefit of insulin is evident from the Diabetes Control and Complication Trial (DCCT) and United Kingdom Prospective Diabetes Study (UKPDS), and the cardiovascular safety of insulin glargine has been demonstrated in individuals with newly diagnosed diabetes or prediabetes in the ORIGIN trial (Outcome Reduction with an Initial Glargine Intervention). The top-line results of DEVOTE (Trial Comparing Cardiovascular Safety of Insulin Degludec vs. Insulin Glargine in Patients with Type 2 Diabetes at High Risk of Cardiovascular Events) have proven the cardiovascular safety of insulin degludec in persons with type 2 diabetes. In this commentary I discuss the interrelationship of insulin and cardiovascular health, while comparing the results of DEVOTE and ORIGIN.
\end{abstract}

Enhanced content To view enhanced content for this article go to http://www.medengine.com/Redeem/ 5A87F0601BE3BF74.

S. Kalra $(\bowtie)$

Department of Endocrinology, Bharti Hospital,

Karnal, India

e-mail: brideknl@gmail.com
Keywords: Cardiovascular outcome trials; Hypoglycaemia; Insulin; Insulin analogues; Nocturnal hypoglycaemia; Type 2 diabetes

Insulin is a well-established treatment for both type 1 and type 2 diabetes and has been in use now for nearly a century. During this time, the source, structure, purity and delivery of insulin has changed significantly. What has not changed, however, is the ability of insulin to control blood glucose, improve quality of life, avoid complications and save lives. The ability of insulin to prevent micro- and micro-vascular complications has been demonstrated in two landmark trials, namely the Diabetes Control and Complication Trial (DCCT) and the United Kingdom Prospective Diabetes Study (UKPDS) $[1,2]$.

While the above-mentioned benefits of insulin are not disputed, the occurrence of side effects, such as weight gain and hypoglycaemia, did lead to concerns about the cardiovascular safety of this drug [3-5]. One large study reported that intensive and rapid glycaemic control measures using insulin as one of many interventional components increased the risk of cardiovascular events and all-cause mortality [3]. The authors, however, did comment that the study was not designed to identify the particular component causing increased events. A meta-analysis also showed that fasting hyperinsulinemia is significantly associated with 
cardiovascular mortality in non-diabetic adults [6]. However, this hyperinsulinemia may be due to insulin resistance, which itself is linked to cardiovascular dysfunction.

Certain insulin analogues were also thought to be linked to increased cancer risk because of their growth-promoting properties [7-12]. Unfounded concerns about the "pushing "of insulin by manufacturers added fuel to fire [13]. These uncertainties led to a debate on whether insulin use to achieve euglycemia in type 2 diabetes follows the dictum 'primum succurrere' (first hasten to help) without respecting the philosophy of 'primum non nocere' (first do not harm). However, these issues, raised by non-specialists in the field, have effectively been put to rest with the ORIGIN and DEVOTE trials.

The ORIGIN trial (Outcome Reduction with an Initial Glargine Intervention) showed insulin glargine to have cardiovascular safety when administered to participants with newly diagnosed type 2 diabetes or prediabetes [14]. The authors of the ORIGIN trial highlighted the large difference in insulin use between the insulin glargine and control group, as well as the glycaemic equipoise achieved between them. Hence, the cardiovascular safety demonstrated in the intervention (glargine) group related more to glargine or insulin per se than to good glycaemic control.

The DEVOTE trial Trial (Comparing Cardiovascular Safety of Insulin Degludec vs. Insulin Glargine in Patients with Type 2 Diabetes at High Risk of Cardiovascular Events) studied 7637 participants with type 2 diabetes and a high cardiovascular risk profile who were being treated with one or more oral or injectable anti-diabetic agent, with a glycated haemoglobin A1c (HbA1c) of $>7.0 \%$. Participants with a HbA1c of $<7.0 \%$ were included in the trial if their current basal insulin requirement was $>20 \mathrm{U} /$ day. All participants were randomized in a double-blinded manner, in a 1:1 ratio, to either an insulin degludec + standard of care arm or an insulin glargine + standard of care arm. They were seen weekly for 2 weeks, monthly for 6 months and quarterly for the rest of the trial [15]. This trial design differed from ORIGIN with respect to inclusion criteria, trial structure and choice of comparator arm and frequency of follow-up (Table 1). It must be noted that ORIGIN had a placebo arm, while DEVOTE used an active comparator arm.

The DEVOTE trial included participants with a longer duration of diabetes and a higher cardiovascular risk profile. The inclusion criteria were reflective of a real world diabetes outdoor clinic which included participants of a similar background who could be initiated on (or switched to) a basal insulin analogue. The primary endpoint of the study, i.e. the MACE composite outcome of first occurrence of cardiovascular death, non-fatal stroke and myocardial infarction, showed a hazard ratio of 0.91 in favour of degludec relative to insulin glargine U100, but this difference was not statistically significant [16]. Thus, degludec demonstrated cardiovascular safety, relative to glargine, allaying concerns about its use in type 2 diabetes patients at risk of cardiovascular disease.

The secondary endpoint, i.e. hypoglycaemia, occurred in fewer participants on degludec than in those on glargine. While $27 \%$ fewer participants in the degludec arm experienced an episode of severe hypoglycaemia, there was a $40 \%$ reduction in the number of total episodes of adjudicated severe hypoglycaemia and a 54\% relative reduction in the rate of nocturnal severe hypoglycaemia, with all these difference achieving statistical significance. These results are concordant with those reported in the BEGIN and BOOST clinical trial programmes of insulin degludec and degludec aspart $[17,18]$.

Hypoglycaemia per se is a risk factor for cardiovascular mortality and is known to impair quality of life $[19,20]$. Hence, avoidance of hypoglycaemia is one of the aims of safe and effective diabetes care and is included in the glycaemic pentad [21].

While detailed data of the DEVOTE trial will be reported at a later time, the top-line results are encouraging. The trial provides evidence that one can use insulin degludec to achieve better glycaemic control without fear of hypoglycaemia and without fear of cardiovascular adverse effects. This will encourage the timely use of insulin in persons with type 2 diabetes, including those with cardiovascular risk factors. In the debate between two contrasting 


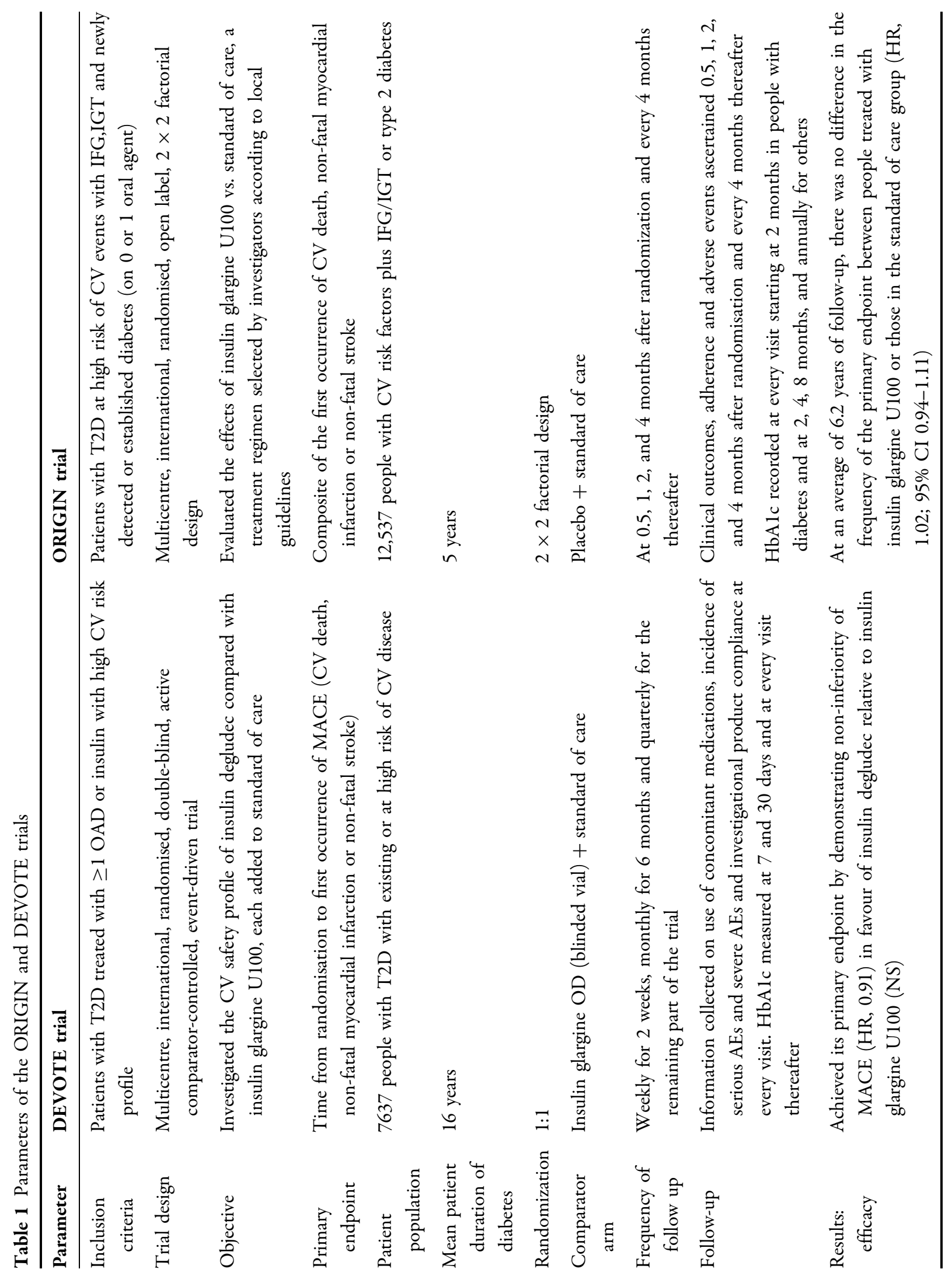




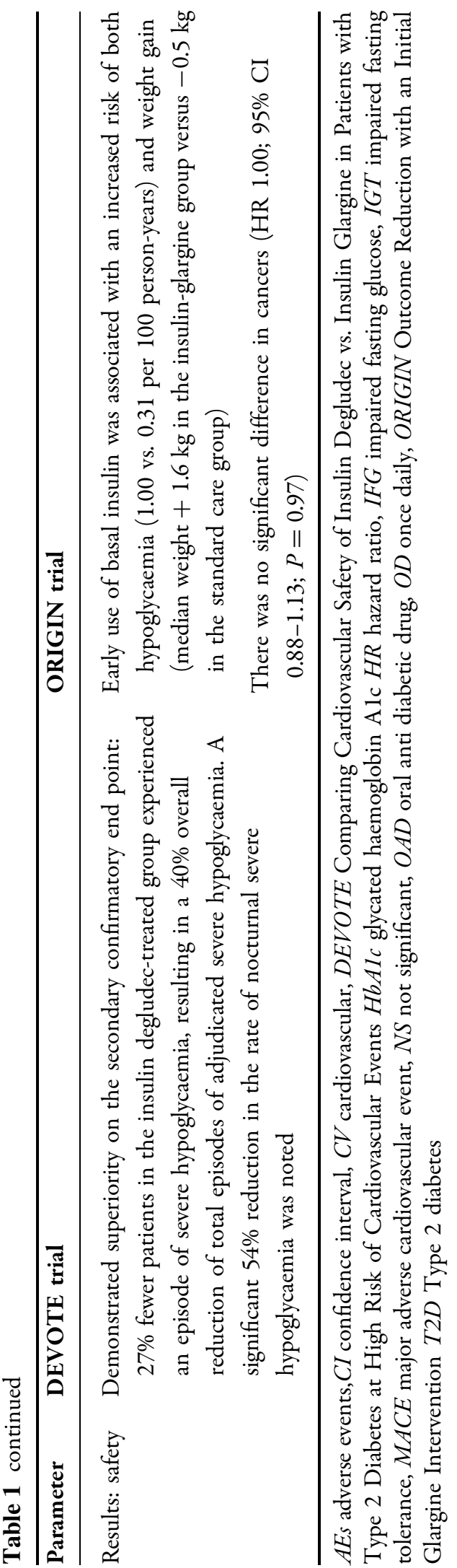

philosophies of action, 'Primum succurrere', and 'Primum non nocere', degludec proves its DEVOTion to diabetes care: Auxiliendo, Primum non nocere.

\section{ACKNOWLEDGEMENTS}

No funding or sponsorship was received for this study or publication of this article. The author meets the International Committee of Medical Journal Editors (ICMJE) criteria for authorship for this manuscript, take responsibility for the integrity of the work as a whole, and has given final approval for the version to be published.

Disclosures. Sanjay Kalra has received speaker fees and advisory board honoraria from Sanofi and Novo Nordisk.

Compliance with Ethics Guidelines. This article is based on previously conducted studies and does not involve any new studies of human or animal subjects performed by the author.

Open Access. This article is distributed under the terms of the Creative Commons Attribution-NonCommercial 4.0 International License (http://creativecommons.org/licenses/ by-nc/4.0/), which permits any noncommercial use, distribution, and reproduction in any medium, provided you give appropriate credit to the original author(s) and the source, provide a link to the Creative Commons license, and indicate if changes were made.

\section{REFERENCES}

1. The Diabetes Control and Complications Trial Research Group. The effect of intensive treatment of diabetes on the development and progression of long-term complications in insulin-dependent diabetes mellitus. N Engl J Med. 1993;329(14):977-86.

2. Holman R, Paul S, Bethel A. Ten-year follow-up of intensive glucose control in type 2 diabetes. J Vasc Surg. 2009;49(1):272.

3. Gerstein HC, Miller ME, Byington RP, Goff DC Jr, Bigger JT, Buse JB, et al. Effects of intensive glucose 
lowering in type 2 diabetes. $\mathrm{N}$ Engl J Med. 2008;358(24):2545-59. doi:10.1056/ NEJMoa0802743 (Epub 2008 Jun 6).

4. Patel A, MacMahon S, Chalmers J, Neal B, Billot L, Woodward M, et al. Intensive blood glucose control and vascular outcomes in patients with type 2 diabetes. N Engl J Med. 2008;358(24):2560-72. doi:10. 1056/NEJMoa0802987 (Epub 2008 Jun 6).

5. Duckworth W, Abraira C, Moritz T, Reda D, Emanuele N, Reaven PD, et al. Glucose control and vascular complications in veterans with type 2 diabetes. N Engl J Med. 2009;360(2):129-39. doi:10. 1056/NEJMoa0808431 (Epub 2008 Dec 17).

6. Lakka HM, Lakka TA, Tuomilehto J, Sivenius J, Salonen JT. Hyperinsulinemia and the risk of cardiovascular death and acute coronary and cerebrovascular events in men: the Kuopio Ischaemic Heart Disease Risk Factor Study. Arch Intern Med. 2000;160(8):1160-68. doi:10.1001/archinte.160.8. 1160 .

7. Hemkens LG, Grouven U, Bender R, Günster C, Gutschmidt S, Selke GW, et al. Risk of malignancies in patients with diabetes treated with human insulin or insulin analogues: a cohort study. Diabetologia. 2009;52(9):1732-44. doi:10.1007/ s00125-009-1418-4 (Epub 2009 Jun 30).

8. Jonasson JM, Ljung R, Talbäck M, Haglund B, Gudbjörnsdòttir S, Steineck G. Insulin glargine use and short-term incidence of malignancies-a population-based follow-up study in Sweden.Diabetologia. 2009;52(9):1745-54. doi:10.1007/s00125-0091444-2 (Epub 2009 Jul 9).

9. Colhoun HM, Kernthaler J, Sullivan F, McGilchrist M, Judson A, Greig L, et al. Use of insulin glargine and cancer incidence in Scotland: a study from the Scottish Diabetes Research Network Epidemiology Group. Diabetologia. 2009;52(9):1755-65. doi:10. 1007/s00125-009-1453-1 (Epub 2009 Jul 15).

10. Currie CJ, Poole CD, Gale EA. The influence of glucose-lowering therapies on cancer risk in type 2 diabetes. Diabetologia. 2009;52(9):1766-77. doi:10. 1007/s00125-009-1440-6 (Epub 2009 Jul 2).

11. Smith U, Gale EA. Editorial: Does diabetes therapy influence the risk of cancer? Diabetologia. 2009;52(9):1699-708. doi:10.1007/s00125-0091441-5.

12. Bowker SL, Majumdar SR, Veugelers P, Johnson JA. Increased cancer-related mortality for patients with type 2 diabetes who use sulfonylureas or insulin. Diabetes Care. 2006; 29(2):254-8.

13. Singh R. Pushing diabetics to take insulin is a medical scam: Fiona Godlee. http://economictimes. indiatimes.com/opinion/interviews/tackle-lifestyleissues-for-diabetes-avoid-insulin-fiona-godlee/article show/55518341.cms. Accessed Dec 11, 2016.

14. Gerstein HC, Bosch J, Dagenais GR, Díaz R, Jung H, Maggioni AP, et al. Basal insulin and cardiovascular and other outcomes in dysglycemia. N Engl J Med. 2012;367(4):319-28. doi:10.1056/NEJMoa1203858 (Epub 2012 Jun 11).

15. Marso SP, McGuire DK, Zinman B, Poulter NR, Emerson SS, Pieber TR, et al. Design of DEVOTE (Trial Comparing Cardiovascular Safety of Insulin Degludec vs Insulin Glargine in Patients With Type 2 Diabetes at High Risk of Cardiovascular Events)DEVOTE 1. Am Heart J. 2016;179:175-83. doi:10. 1016/j.ahj.2016.06.004 (Epub 2016 Jun 18).

16. Novo Nordisk A/S. Tresiba ${ }^{\circledR}$ demonstrates a safe cardiovascular profile and reduces the risk of severe hypoglycaemia compared to insulin glargine U100 in the DEVOTE trial. https://globenewswire.com/newsrelease/2016/11/29/893585/0/en/Novo-Nordisk-A-STresiba-demonstrates-a-safe-cardiovascular-profileand-reduces-the-risk-of-severe-hypoglycaemia-compared-to-insulin-glargine-U100-in-the-DEVOTE-trial. html. Accessed Jan 27, 2017.

17. Zinman B, Philis-Tsimikas A, Cariou B, Handelsman Y, Rodbard HW, Johansen T, et al. Insulin degludec versus insulin glargine in insulin-naive patients with type 2 diabetes: a 1-year, randomized, treat-to-target trial (BEGIN Once Long). Diabetes Care. 2012;35(12):2464-71. doi:10.2337/dc12-1205 (Epub 2012 Oct 5).

18. Rodbard HW, Cariou B, Zinman B, Handelsman Y, Philis-Tsimikas A, Skjøth TV, et al. Comparison of insulin degludec with insulin glargine in insulin-naive subjects with Type 2 diabetes: a 2-year randomized, treat-to-target trial. Diabet Med. 2013;30(11):1298-304. doi:10.1111/dme.12303 (Epub 2013 Sep 30).

19. Heller SR, Choudhary P, Davies C, Emery C, Campbell MJ, Freeman J, et al. Risk of hypoglycaemia in types 1 and 2 diabetes: effects of treatment modalities and their duration. Diabetologia. 2007;50(6):1140-7 (Epub 2007 Apr 6).

20. Harris S, Mamdani M, Galbo-Jørgensen CB, Bøgelund M, Gundgaard J, Groleau D. The effect of hypoglycemia on health-related quality of life: Canadian results from a multinational time trade-off survey. Can J Diabetes. 2014;38(1):45-52. doi:10.1016/j.jcjd.2013.09.001.

21. Kalra S. Hypoglycaemia in diabetes. J Pak Med Assoc. 2014;64(9):1090-3. 